\title{
Relationship between chronological age and skeletal maturity of wrist joint and hand in a sample of Nepalese population: A radiographic study
}

\author{
Parajuli SR, ${ }^{1}$ D $\otimes$, Gautam R, ${ }^{2}$ iD Timsinha S, ${ }^{3}$ iD Sharma P4 iD \\ 'Sudhir Raman Parajuli, Lecturer, Department of Forensic Medicine; ${ }^{2}$ Rabin Gautam, Researcher, Department of Community \\ Medicine; ${ }^{3}$ Sidarth Timsinha, Associate Professor, Department of Forensic Medicine; ${ }^{4}$ Prakash Sharma, Associate Professor, \\ Department of Radiodiagnosis, Manipal College of Medical Sciences, Pokhara, Kaski, Nepal.
}

\begin{abstract}
Background: The human body grows and matures with age, especially in children and adolescents. Skeletal age is determined from the development stage of bones.

Objectives: To determine the age of epiphyseal fusion of the lower end of radius and ulna in the Nepalese population which is important from a medicolegal point of view.

Methods: An analytical cross-sectional study was conducted on patients undergoing X-rays of hand and wrist attending Manipal Teaching Hospital, Pokhara in a one-year period from January 1, 2019 to December 31, 2019. Total sample was 90 cases. The X-rays were assessed as appearance and not-appearance of epiphysis and different phases of skeletal maturity were graded according to McKern and Stewart classification.

Results: Mean age was relatively higher in males in fusion of radius. Whereas in ulna, no difference was recorded in mean age in the fifth stage. In male the correlation coefficient for stage of fusion for radius and ulna with age (years) was 0.90 and $0.65(p<0.001)$, while for the females the correlation coefficient for stage of fusion of radius and ulna with age was 0.94 and $0.82(p<0.001)$, both indicating a strong correlation.

Conclusion: Estimation of age is not only important for identification of the deceased victim but also in medicolegal issues where there are many cases in courts which are undergoing age assessment by experts in absence of birth certificate or counterfeit documents.
\end{abstract}

Key words: Epiphyses; Wrist; X-rays.

Access this article online

Website: www.jkmc.com.np

DOI: https://doi.org/10.3126/jkmc.v10i1.38946

HOW TO CITE

Parajuli SR, Gautam R, Timsinha S, Sharma P. Relationship between chronological age and skeletal maturity of wrist joint and hand in a sample of Nepalese population: A radiographic study. J Kathmandu Med Coll. 2021;10(1):11-6.

Address for correspondence

Dr. Sudhir Raman Parajuli

Lecturer, Department of Forensic Medicine

Manipal College of Medical Sciences, Pokhara, Kaski, Nepal.

E-mail: sudeer88.sp@gmail.com

Copyright $\odot 2021$ Journal of Kathmandu Medical College (JKMC)

ISSN: 2019-1785 (Print), 2091-1793 (Online)

(i) (8) This work is licensed under a Creative Commons Attribution-Non Commercial 4.0 International License.

\section{INTRODUCTION}

Tuman body grows and matures with age, especially in children and adolescents. ${ }^{1}$ Skeletal age is determined from developmental stage of bones. To estimate an individual's age for whom proper documentation is not available, forensic practitioners must rely on population data concerning growth and development. ${ }^{2}$ For precise age determination, radiological standards of development of knee, foot, ankle, and especially hand-and-wrist are relied upon. Criteria for evaluating hand radiographs include the degree of epiphyseal ossification. ${ }^{3}$ However, due to individual variation in timing of skeletal and dental development, results of any method are subject to uncertainty when applied to a single individual. ${ }^{4}$

Various longitudinal studies on radiographic data from wrist development have been collected and a number of 
reference standard results are obtained which are used in age estimation, and all are based on radiographic assessment. However, different methods are associated with varying degrees of uncertainty and precision, and this is not always well understood. ${ }^{5}$ The authors could not find a similar study done in Nepal.

This study was meant to determine epiphyseal fusion age of lower end of radius and ulna in Nepalese population. The results of this study will be important from a medicolegal point of view to ascertain individual age.

\section{METHODOLOGY}

An analytical cross-sectional study was conducted on patients undergoing $\mathrm{X}$-rays of hand and wrist attending Manipal Teaching Hospital, Pokhara in a one-year period from January 1, 2019 to December 31, 2019. The convenience sampling was utilised to record the cases from the outpatient and the emergency department of the hospital. Total of 95 cases were recorded over the one-year period. All X-rays of hand and wrist joints of age group six to 20 years were included which showed a clear stage of fusion. Individuals with known endocrine, nutritional, or developmental disorders, and of age above 20 years were excluded from study. Out of the 95 cases, five cases were not taken into consideration due to the exclusion criteria. With this the total sample of 90 cases were taken for this study during the one-year period.

Ethical approval was obtained from the Institutional Review Committee, Manipal College of Medical Sciences (Ref. MEMG/IRC/172/GA). Written consent was taken from parents and participants as required. Right side was taken for study.

Age was determined based on history and through documents available confirming age of an individual whenever possible. The $\mathrm{X}$-rays were assessed as appearance and not-appearance of epiphysis and different phases of skeletal maturity were graded according to McKern and Stewart (1957). ${ }^{6}$ Classification on epiphyseal union (stage of fusion) which subdivides the continuum of epiphyseal union into five stages is shown.

\begin{tabular}{ll}
\hline Stage & \multicolumn{1}{c}{ Description } \\
Stage 1(1) & $\begin{array}{l}\text { Nonunion - when the epiphyseal cartilage } \\
\text { did not begin to decrease in thickness }\end{array}$ \\
& $\begin{array}{l}\text { Commence of union - when the thickness of } \\
\text { epiphysial cartilage was found to be reduced } \\
\text { appreciably (1/4th united) }\end{array}$
\end{tabular}

Incomplete union - when the epiphysis has

Stage 3(3) begun to fuse with shaft and complete union was well underway ( $1 / 2$ united)

Complete union - when the epiphyseal cartilage was bony in architecture and its

Stage 4(4) density indistinguishable from the epiphysis and diaphysis in its neighborhood but an epiphysial line called epiphysial scar could still be distinguished. (3/4 united)

Stage 5(5) Complete union - with absence of epiphyseal scar

Zero (0) is designated for the appearance of bone and not appearing means the epiphyseal end has not appeared at all. The data was entered, cleaned, and coded in Microsoft Excel and transferred and analysed through Statistical Package for the Social Sciences (SPSS) Statistics for Windows, version 16.0 (SPSS Inc., Chicago, III., USA).

\section{RESULTS}

A total of 90 subjects were included in the study. It was seen that there was an increase in the stage of fusion with increasing age. Of the 90 subjects $54(60 \%)$ were females and $36(40)$ were males. The mean age of the participants was $16.14 \pm 3.81$ years.

The distribution of subjects with age and stage of fusion are presented in Tables 1 and 2.

The progression of fusion with increasing chronological age is evident from Table 3. The mean age showed a gradual increase with stages of union and variation between male and female subjects. Mean age was relatively higher in males in fusion of radius. Whereas, in ulna, no difference was recorded in mean age in the fifth stage.

Almost complete fusion (F5) of both radius and ulna was found in age more than 17 years whereas in males it was found a year later. Distal end of ulna did not show appearance till 10 years of age in females and nine years in male. However, data was missing to be concise.

To determine the stage of relationship between the age and stage of fusion correlation test was done. In male the correlation coefficient for stage of fusion for radius and ulna with age (years) was 0.90 and 0.65 ( $p<0.001$ ) respectively, indicating strong correlation. While for the females the stage of fusion of radius and ulna were strongly correlated with age $(0.94$ and $0.82(p<0.001)$ respectively). 
Table 1: Different stage of fusion of radius and ulna among females

\begin{tabular}{|c|c|c|c|c|c|c|c|c|c|c|c|c|c|c|}
\hline \multirow[b]{2}{*}{$\mathbf{n}$} & \multirow[b]{2}{*}{ Age (in years) } & \multicolumn{6}{|c|}{ Radius (fusion stage) } & \multicolumn{7}{|c|}{ Ulna (fusion stage) } \\
\hline & & 0 & 1 & 2 & 3 & 4 & 5 & Not appeared & 0 & 1 & 2 & 3 & 4 & 5 \\
\hline 3 & $6-6.9$ & 3 & & & & & & 3 & & & & & & \\
\hline 1 & $7-7.9$ & & 1 & & & & & 1 & & & & & & \\
\hline 1 & $8-8.9$ & & & 1 & & & & 1 & & & & & & \\
\hline 2 & $9-9.9$ & & 1 & 1 & & & & 2 & & & & & & \\
\hline 0 & $10-10.9$ & & & & & & & & & & & & & \\
\hline 0 & $11-11.9$ & & & & & & & & & & & & & \\
\hline 3 & $12-12.9$ & & 1 & 2 & & & & & & 1 & 2 & & & \\
\hline 3 & $13-13.9$ & & 1 & 2 & & & & & 1 & & 1 & 1 & & \\
\hline 3 & $14-14.9$ & & & 1 & 2 & & & & & 1 & & 2 & & \\
\hline 1 & $15-15.9$ & & & & & 1 & & & & & & & & 1 \\
\hline 5 & $16-16.9$ & & & & & 5 & & & & & & & 5 & \\
\hline 6 & $17-17.9$ & & & & & 1 & 5 & & & & & & 1 & 5 \\
\hline 9 & 18-18.9 & & & & & & 9 & & & & & & & 9 \\
\hline 19 & 19-19.9 & & & & & & 19 & & & & & & 2 & 17 \\
\hline
\end{tabular}

Table 2: Different stage of fusion of radius and ulna among males

\begin{tabular}{|c|c|c|c|c|c|c|c|c|c|c|c|c|c|c|}
\hline \multirow[b]{2}{*}{$\mathbf{n}$} & \multirow[b]{2}{*}{ Age (in years) } & \multicolumn{6}{|c|}{ Radius (fusion stage) } & \multicolumn{7}{|c|}{ Ulna (fusion stage) } \\
\hline & & 0 & 1 & 2 & 3 & 4 & 5 & Not appeared & 0 & 1 & 2 & 3 & 4 & 5 \\
\hline 1 & 6-6.9 & 1 & & & & & & 1 & & & & & & \\
\hline 1 & $7-7.9$ & 1 & & & & & & 1 & & & & & & \\
\hline 1 & $8-8.9$ & & 1 & & & & & 1 & & & & & & \\
\hline 0 & $9-9.9$ & & & & & & & & & & & & & \\
\hline 0 & $10-10.9$ & & & & & & & & & & & & & \\
\hline 0 & $11-11.9$ & & & & & & & & & & & & & \\
\hline 1 & $12-12.9$ & & 1 & & & & & & 1 & & & & & \\
\hline 0 & 13-13.9 & & & & & & & & & & & & & \\
\hline 1 & $14-14.9$ & & & 1 & & & & & & & & 1 & & \\
\hline 4 & $15-15.9$ & & & 1 & & 3 & & & & & & 2 & 1 & 1 \\
\hline 6 & $16-16.9$ & & & & 1 & 5 & & & & & & 1 & 2 & 3 \\
\hline 3 & $17-17.9$ & & & 1 & & 2 & & & & & 1 & 1 & & 1 \\
\hline 5 & $18-18.9$ & & & & & & 5 & & & & & 2 & & 3 \\
\hline 11 & 19-19.9 & & & & & & 11 & & & & & & & 11 \\
\hline
\end{tabular}


Table 3: Mean and range of age for each stage of union at each of the epiphysis at the wrist for males and females

\begin{tabular}{|c|c|c|c|c|c|c|c|c|c|c|}
\hline & & Female & & & Mean age (years) & & Male & & & Mean age (years) \\
\hline & $\mathbf{n}$ & Stage of union & (a) & (b) & $\pm S D$ & $\mathbf{n}$ & Stage of union & (a) & (b) & $\pm S D$ \\
\hline \multirow[t]{6}{*}{ Radius } & 3 & 0 & 6 & 6 & $6.0 \pm 0$ & 2 & 0 & 6 & 7 & $6.5 \pm 0.5$ \\
\hline & 4 & 1 & 7 & 13 & $9.5 \pm 3$ & 2 & 1 & 8 & 12 & $9.8 \pm 2$ \\
\hline & 7 & $2^{*}$ & 8 & 14 & $10.6 \pm 3$ & 3 & 2 & 14 & 17 & $15.4 \pm 1.5$ \\
\hline & 2 & 3 & 14 & 14 & $14.0 \pm 0$ & 1 & 3 & 16 & 16 & $16.0 \pm 0$ \\
\hline & 7 & 4 & 15 & 17 & $16.0 \pm 1$ & 10 & 4 & 15 & 17 & $16.0 \pm 1$ \\
\hline & 33 & 5 & 17 & 20 & $18.4 \pm 1.5$ & 16 & 5 & 18 & 20 & $19.0 \pm 1$ \\
\hline \multirow[t]{7}{*}{ Ulna } & 7 & Not appeared & 6 & 9 & $7.3 \pm 1.5$ & 3 & Not appeared & 6 & 8 & $6.9 \pm 1$ \\
\hline & 1 & 0 & 13 & 13 & $13.0 \pm 0$ & 1 & 0 & 12 & 12 & $12.0 \pm 0$ \\
\hline & 2 & 1 & 12 & 14 & $13.0 \pm 1$ & 0 & 1 & 0 & 0 & \\
\hline & 3 & 2 & 12 & 13 & $12.5 \pm 0.5$ & 1 & 2 & 17 & 17 & $17.0 \pm 0$ \\
\hline & 3 & $3^{*}$ & 13 & 14 & $13.5 \pm 0.5$ & 7 & 3 & 14 & 18 & $15.9 \pm 2$ \\
\hline & 8 & 4 & 16 & 18 & $17.0 \pm 1$ & 3 & 4 & 15 & 16 & $15.5 \pm 0.5$ \\
\hline & 32 & 5 & 15 & 20 & $17.3 \pm 2.5$ & 19 & 5 & 15 & 20 & $17.3 \pm 2.5$ \\
\hline
\end{tabular}

*A significant difference was recorded at this stage of union in between male and female mean age; (a) minimum age of stage of union; (b) maximum age of stage of union.

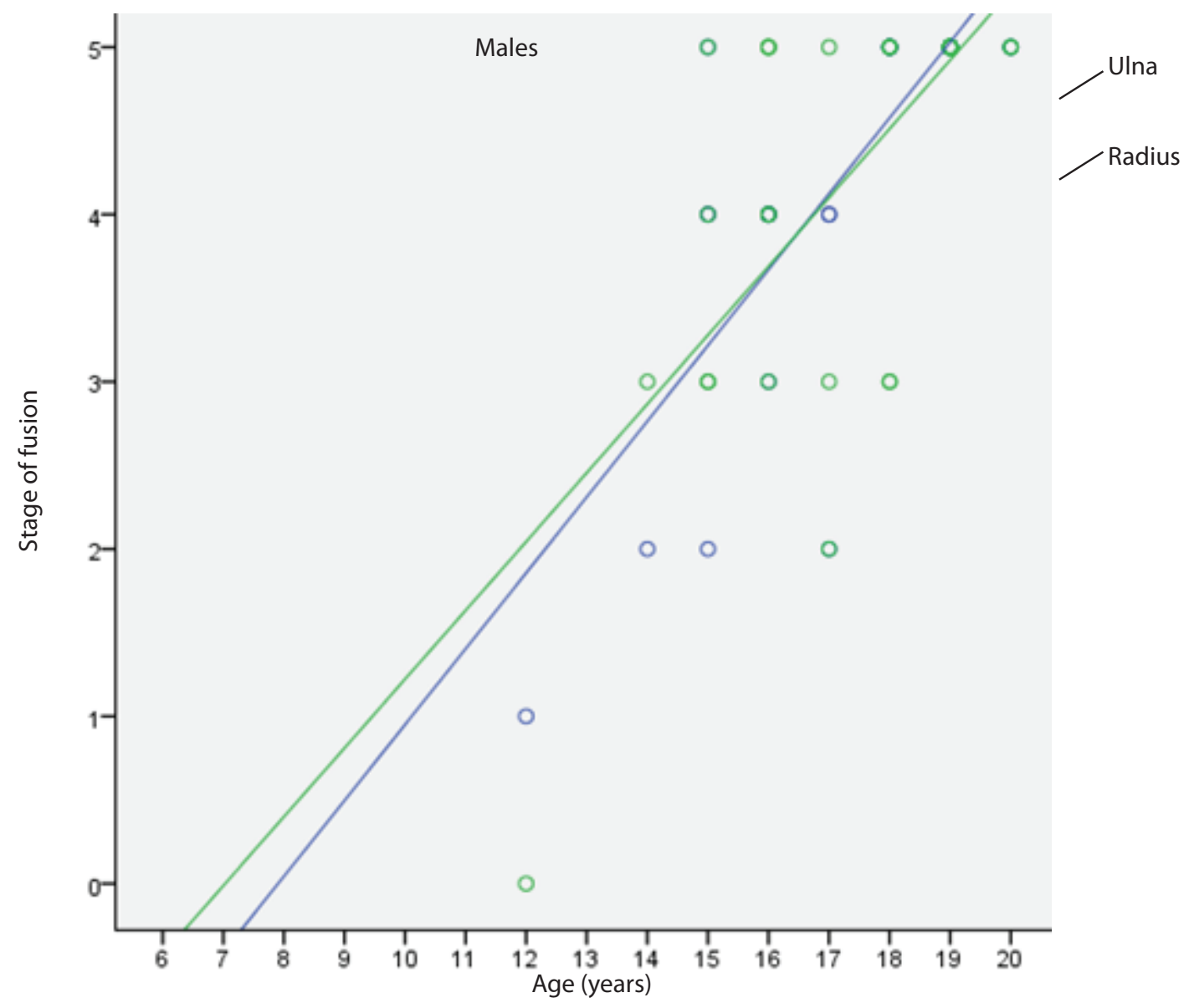

Figure 1: Scatter plot showing correlation between age and stage of fusion for males 


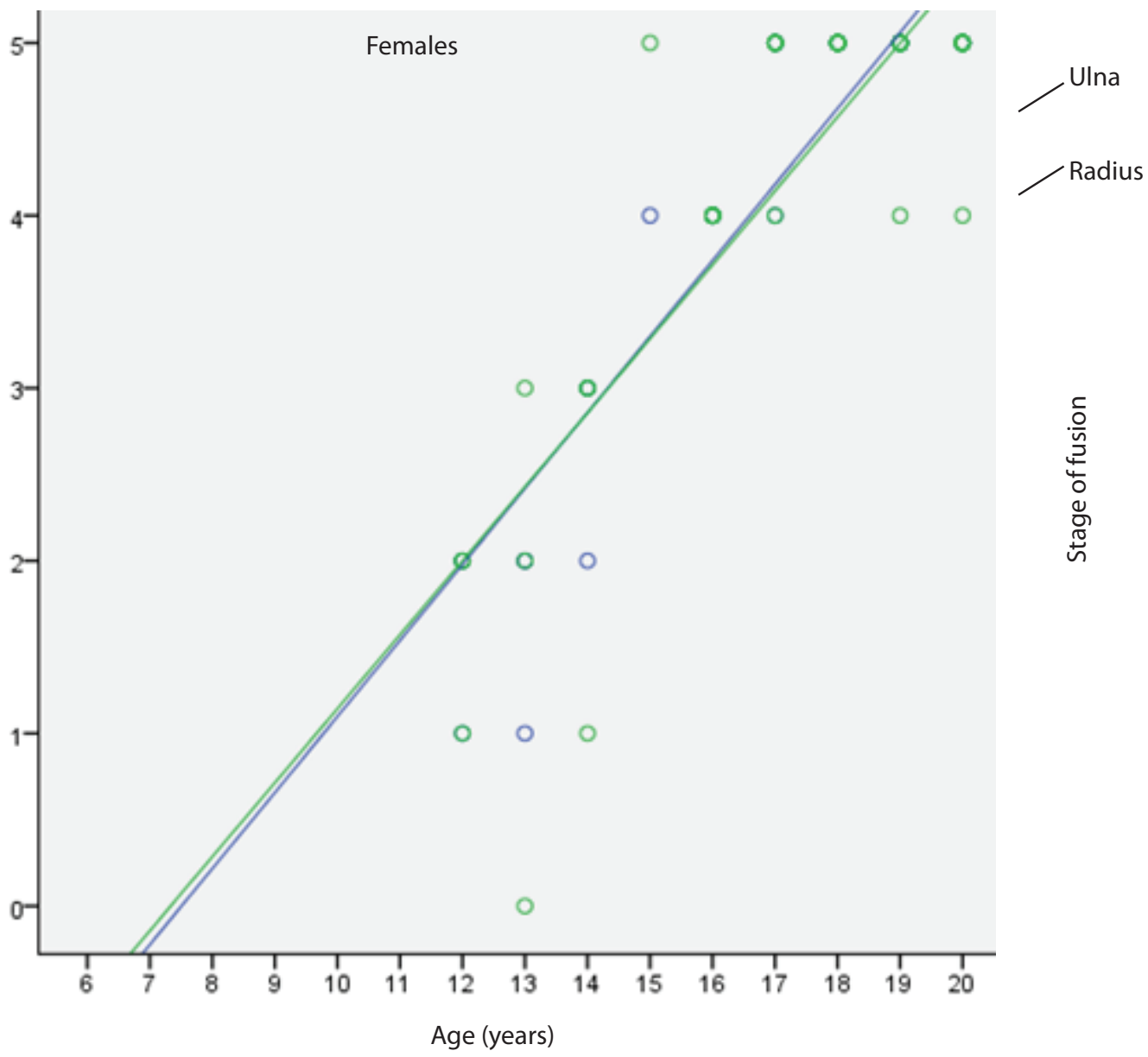

Figure 2: Scatter plot showing correlation between age and stage of fusion for females

\section{DISCUSSION}

There is no method currently available that can reliably provide the chronological age of an individual with any useful degree of accuracy. Age determination based on epiphyseal fusion is considered one of the most important scientific tools till date. Current methods provide, at best, a range within which the subject's chronological age is likely to fall. Moreover, because of the rapid and irregular pace of maturation, secondary characteristics fail to get good results. ${ }^{7}$

In Nepal, the Juvenile Justice Reform Regulations (2063) implicitly recognises the lack of reliability of medical/ dental age assessment and considers birth certificates issued by a hospital, the most reliable indicator. An age assessment conducted by a government hospital is accepted only when those are not available or falsified undergoing criminal proceedings. ${ }^{8}$

This study particularly focussed on the stage of fusion of distal radius and ulna and involved age groups from six to
20 years. As per the recommendations of the Study Group on Forensic Age Diagnostics, a forensic age estimate should consist of a physical examination, an X-ray of the hand, and a dental examination which records dentition status and evaluates an orthopantomogram. ${ }^{9}$ This is done when minimal X-ray has to be done.

The study carried out between the age group of 10 to 20 years in Kavrepalanchok district of Nepal found the epiphyseal fusion at the distal end of radius and ulna to be hundred percent at the age of 18-19 years in males and 17-18 years in females which is almost similar to current study and corroborates with the findings. ${ }^{2}$ Slight variation was found in age estimation for both male and female population conducted in Mumbai region of India by Bhishe et al. and is found similar to present study and thus lays stress on region related study for more accurate findings. ${ }^{10}$

Almost all studies confirm early fusion of bones on male, compared to females which is found in our study too. ${ }^{11}$ 
Thus, age estimation requires separate assessment for fusion in both males and females as per the study. Further studies involving a larger number of cases is needed to effectively comment on the fusion and age. Age determination of living individuals is crucial in many legal issues. The evidence produced by present study through radiological imaging can serve a scientific basis for anthropometry and medicolegal examination. Skeletal age evaluated by the sequence of fusion of epiphyses of long bones and development of centers of ossification in small bones can therefore help in assessing the age of the concerned sample/accused. Further studies involving a larger number of cases is needed to effectively comment on the fusion and age. However, this study adds one brick for age assessment from radiography in Nepalese population.

\section{CONCLUSION}

To conclude, chronologic age and skeletal maturity was well correlated with the epiphyseal fusion at wrist joint in Nepalese population. It was seen that with increasing age there was a greater stage of fusion at the joint. The radiographic assessment offers a valuable alternative as a non-invasive method of estimation of age. This study provides support to use the stage of fusion as an alternative method for estimating the age. The results can be used as a baseline data for Nepalese population though the population variation as per ethnicity might be there, which is again a topic for further research.

\section{ACKNOWLEDGEMENTS}

I would like to acknowledge Sandipa Kafle, Dr. Uttam Bista, Nabaraj Karki, and the Department of Radiology of Manipal Teaching Hospital for helping me with the data collection and other necessary support.

\section{Conflict of interest: None Source(s) of support: None}

\section{REFERENCES}

1. Bangal R, Bhise $S$, Nanandkar S. Age determination from tri-radiate cartilage fusion-A radiological study in Mumbai region. J Indian Acad Forensic Med. 2016;38(3):271. [Full Text | DOI]

2. Guidelines of Forensic age estimation for living Individuals in Nepal [Internet]. [cited 2020 Jul 28]. Available from: http://meleson.org/wp-content/ uploads/2017/09/Guidelines-compiled.pdf [Full Text]

3. Brogdon MD. Forensic Radiology. CRC Press; c1998. Chapter 5, Radiological Identification: Anthropological Parameters; p.68 [Full Text]

4. Schmeling A, Dettmeyer R, Rudolf E, Vieth V, Geserick G. Forensic age estimation: Methods, certainty, and the law. Dtsch Arztebl Int. 2016 Jan 29;33(4):243-5. [Full Text | DOI]

5. Kumar A, Parveen G, Srivastava R, Wadhwani P, Ali I, Awasthi P. Determination of age and sex and identification of deceased person by forensic procedures. Univers Res J Dent. 2014;4(3):153. [Full Text | DOI]

6. Washburn SL. Skeletal age changes in young American males, analysed from the standpoint of age identification. Thomas W. McKern and T. D. Stewart.
Technical Report EP-45, Environmental Protection Research Division, Quartermaster Research and Development Center, U.S. A. Am Antiq. 1957th ed. 1958 Oct 20;24(2):198-9. [Full Text]

7. Franklin D, Flavel A, Noble J, Swift L, Karkhanis S. Forensic age estimation in living individuals: methodological considerations in the context of medicolegal practice. Res Reports Forensic Med Sci. 2015; 5:5366. [Full Text | DOI]

8. Nepal Law Comission, Age determination [Internet]. [cited 2020 Jul 22]. Available from: http://www. lawcommission.gov.np/en/archives/7144 [Full Text]

9. Schmeling A, Olze A, Reisinger W, Rösing FW, Geserick $\mathrm{G}$. Forensic age diagnostics of living individuals in criminal proceedings. Homo. 2003;54(2):162-9. [PubMed | DOI]

10. Bhise SS, Chikhalkar BG, Nanandkar SD, Chavan GS. Age Determination from Radiological study of epiphysial appearance and union around wrist joint and hand. J Indian Acad Forensic Med. 2011;33(4):292-5. [Full Text]

11. Sangma W, Marak F, Singh M, Kharrubon B. Age determination in girls of north - eastern region of India. J Indian Acad Forensic Med. 2007;29(4):102-8. [Full Text] 